\title{
Óleo essencial de alecrim no controle de doenças e na indução de resistência em videira
}

\author{
Aline José Maia(1), Kátia Regina Freitas Schwan-Estrada(1), Cacilda Márcia Duarte Rios Faria(2), \\ Juliana Santos Batista Oliveira ${ }^{(1)}$, Virlene Amaral Jardinetti ${ }^{(1)}$ e Bruno Neves Batista ${ }^{(1)}$
}

\begin{abstract}
(1)Universidade Estadual de Maringá, Departamento de Agronomia, Avenida Colombo, № 5.790, Jardim Universitário, CEP 87020-900 Maringá, PR, Brasil. E-mail: alymaia2005@yahoo.com.br, krfsestada@uem.br, julianagolmer@hotmail.com, vir_agro@hotmail.com, batistaobruno@hotmail.com (2)Universidade Estadual do Centro Oeste, Departamento de Agronomia, Simeão Camargo Varela de Sá, no 03, Vila Carli, CEP 85040-080 Guarapuava, PR, Brasil. E-mail: criosfaria@hotmaill.com
\end{abstract}

Resumo - O objetivo deste trabalho foi determinar as características químicas do óleo essencial de alecrim e o seu efeito na produtividade, no controle da mancha da folha e do míldio, e na indução de resistência em videira 'Isabel'. O experimento foi realizado em vinhedo comercial, em dois ciclos consecutivos. Os tratamentos consistiram das doses do óleo essencial: 0, 500, 1.000, 2.000 e $4.000 \mu \mathrm{L} \mathrm{L}^{-1}$, além dos tratamentos Tween $80 \%$, calda bordalesa, acibenzolar-S-metil e mancozebe. Foram avaliados a severidade da mancha da folha e do míldio, a atividade das enzimas quitinase e catalase, a massa e o número de cachos e as características químicas das uvas. Houve efeito quadrático das doses do óleo essencial de alecrim, para severidade da mancha da folha e do míldio da videira, nos dois ciclos, com resultados semelhantes aos dos tratamentos com calda bordalesa, acibenzolar-S-metil e mancozeb. Também houve aumento no número e na massa dos cachos, bem como na produtividade. O óleo essencial não interferiu nas características químicas das uvas. Observaram-se aumento na atividade da enzima quitinase e redução na atividade da catalase nas folhas. O óleo essencial nas doses de $500,1.000$ e $2.000 \mu \mathrm{L} \mathrm{L}^{-1}$ é uma alternativa para o controle de doenças da videira 'Isabel'.

Termos para indexação: Rosmarinus officinalis, Vitis labrusca, sustentabilidade, viticultura.

\section{Rosemary essential oil in the control of diseases and induction of resistance in grapevine}

\begin{abstract}
The objective of this work was to determine the chemical qualities of rosemary essential oil and its effect on productivity, on the control of leaf spot and mildew, and on the induction of resistance in 'Isabel' grapevine. The experiment was carried out in a commercial vineyard, in two consecutive cycles. The treatments consisted of the essential oil doses: $0,500,1,000,2,000$, and $4,000 \mu \mathrm{L} \mathrm{L}^{-1}$, besides the Tween $80 \%$, bordeaux mixture, acibenzolar-S-methyl, and mancozeb treatments. Severity of leaf blight and mildew, the activity of chitinase and catalase enzymes, and mass and number of clusters and chemical characteristics of grapes were evaluated. There was a quadratic effect as affected by the doses of essential rosemary oil, for severity of leaf spot and mildew in grapevine, in both cycles, with results similar to those of bordeaux mixture, acibenzolar-S-methyl, and mancozeb. There was also an increase in the number and mass of clusters, as well as in productivity. The essential oil did not affect the chemical characteristics of grapes. An increase in the activity of the chitinase enzyme and a decrease in the catalase activity were observed in leaves. Essential oil at the doses of $500,1,000$, and $2,000 \mu \mathrm{L} \mathrm{L}^{-1}$ is an alternative for the control of diseases in 'Isabel' grapevine.
\end{abstract}

Index terms: Rosmarinus officinalis, Vitis labrusca, sustainability, viticulture.

\section{Introdução}

Entre as doenças de importância para a videira (Vitis labrusca L.), encontra-se o míldio [Plasmopara viticola (Berkeley \& M.A. Curtis) Berleses. \& De Toni] e a mancha da folha, causada por Pseudocercospora vitis (Lév.). Speg. [Syn. Isariopsis clavispora (Berk. \& Curtis) Sacc.], que causam sérios prejuízos à viticultura, por ocasionar efeito negativo na produção ao enfraquecer a planta, em razão da desfolha precoce (Sônego et al., 2003).

Para o controle dessas doenças, têm sido utilizados produtos químicos que podem atingir $30 \%$ do custo de produção da uva. Contudo, o processo produtivo agrícola sofre pressão da sociedade para a produção de alimentos de forma sustentável e sem resíduos (Talamini \& Stadnik, 2004), o que aumenta o interesse pelos métodos alternativos de controle de doenças de 
plantas, com destaque para o uso de extratos vegetais e óleos essenciais (Schwan-Estrada et al., 2012).

Uma das espécies com potencial para substituir os produtos químicos é o alecrim (Rosmarinus officinalis L.), planta arbustiva, lenhosa, ramificada, da família Lamiaceae (Wang et al., 2008), que apresenta, em sua composição, princípios ativos como: 1,8 cineol, a-pineno, borneol, cânfora, acetato de isobomila, valerianato de isonila, ácido cítrico, glicólico, glicínico, rosmarímico, nicotianamida, colina, pectina e rosmaricina. Destes, 1,8 cineol, $\alpha$-pineno, borneol e cânfora têm atividade antimicrobiana conhecida (Gachkar et al., 2007).

De acordo com Santos et al. (2010), os óleos essenciais podem ser uma alternativa com potencial antifúngico na preservação de alimentos; no entanto, são poucos os estudos sobre a indução de resistência obtida pela aplicação desses produtos. Há relatos da eficiência do óleo essencial na inibição in vitro de patógenos (Bettiol \& Morandi, 2009), porém, não há relatos da aplicação de óleos essenciais no controle de doenças de videira, em experimentos desenvolvidos em campo.

A atividade antimicrobiana do óleo essencial de $R$. officinalis no desenvolvimento in vitro de Phytophthora infestans foi observada por Soylu et al. (2006), pela inibição total do patógeno, tanto por contato direto quanto pela ação de compostos voláteis na redução da formação de esporângios e pelas alterações na morfologia das hifas e dos vacúolos do fungo. Resultados semelhantes foram obtidos por Díaz Dellavalle et al. (2011), ao utilizar diferentes extratos de $R$. officinalis sobre o crescimento de Alternaria spp.

$\mathrm{O}$ objetivo deste trabalho foi determinar as características químicas do óleo essencial de alecrim e seu efeito na produtividade, no controle da mancha da folha e do míldio, e na indução de resistência em videira 'Isabel'.

\section{Material e Métodos}

O experimento foi conduzido em vinhedo comercial, com a cultivar Isabel, durante duas safras consecutivas, de agosto a dezembro de 2011 e de fevereiro a julho de 2012. O vinhedo está localizado no Município de Marialva, Paraná $\left(23^{\circ} 27^{\prime} 50^{\prime \prime} \mathrm{S}, 5^{\circ}{ }^{\circ} 7^{\prime} 19^{\prime \prime} \mathrm{W}\right.$, a $614 \mathrm{~m}$ de altitude). O clima da região, conforme classificação de Köppen, é do tipo Cfa, e os solos são classificados como
Latossolo Vermelho eutroférrico e Nitossolo Vermelho eutroférrico de textura muito argilosa e relevo plano a ondulado (Santos et al., 2006). As videiras, que estavam no oitavo ano de produção, foram enxertadas sobre o porta-enxerto $420-\mathrm{A}$, no espaçamento de 2,0x2,5 m, o que totalizou $1.250 \mathrm{~m}^{2}$, e foram conduzidas no sistema de latada.

O óleo essencial de alecrim foi obtido por hidrodestilação, a partir de 2,0 kg de folhas secas ao ar (Worwood, 1995), retiradas do horto localizado na Fazenda Experimental de Iguatemi, na Universidade Estadual de Maringá (UEM), PR. As análises qualitativas do óleo essencial foram realizadas por cromatografia em fase gasosa acoplada à espectrometria de massa (CG-EM) (Ribeiro et al., 2012), no departamento de Química Analítica da UEM.

A identificação dos compostos foi realizada com base no índice de retenção de Kovats (determinado com respeito à série homóloga de n-alcanos, analisada sob as mesmas condições experimentais), na busca na biblioteca NIST MS e por comparação aos dados da literatura (Ribeiro et al., 2012). Os dados quantitativos foram obtidos das percentagens das áreas do cromatograma por meio de normalização. A composição do óleo essencial de alecrim está descrita na Tabela 1.

Os tratamentos consistiram das seguintes doses do óleo essencial de alecrim: 0, 500, 1.000, 2.000 e 4.000 $\mu \mathrm{L} \mathrm{L}^{-1}$, além dos tratamentos padrões com: Tween $80 \%$, utilizado como adjuvante na solubilização do óleo essencial, na proporção 1:1 (óleo essencial de alecrim: Tween $80 \%$ ); calda bordalesa, na proporção 1:1:100 (sulfato de cobre: cal virgem: água); acibenzolar-S-metil, $50 \mathrm{mg} \mathrm{L}^{-1}$; e mancozebe, $3 \mathrm{~kg} \mathrm{ha}^{-1}$ de Dithane.

As pulverizações foram realizadas semanalmente com pulverizador manual até o ponto de "gotejamento", nas horas mais frescas do dia, a partir do início da brotação, em 30/8/2011 e 14/2/2012, o que perfaz um total de dez aplicações. Utilizou-se o delineamento experimental de blocos ao acaso, com nove tratamentos e cinco repetições, e a parcela experimental foi constituída por uma planta.

Com o aparecimento dos primeiros sintomas, a severidade do míldio e da mancha da folha da videira foi avaliada em três folhas da parte mediana de quatro ramos por planta, previamente identificadas, tendose utilizado escalas diagramáticas conforme Azevedo 
(1998) e Lenz et al. (2009), respectivamente. Com os dados da severidade, foi determinada a área abaixo da curva de progresso da doença (AACPD) (Campbell \& Madden, 1990). No total, foram realizadas cinco avaliações com intervalos de sete dias.

Foram avaliadas a produtividade e a qualidade da uva nas duas safras consecutivas. As variáveis analisadas foram: número de cachos por parcela e massa média dos cachos. Com os dados obtidos, estimou-se a produtividade $\left(\mathrm{Mg} \mathrm{ha}^{-1}\right)$. Para determinar as características químicas, foram coletados três frutos por parcela, que foram triturados em extratora de suco, tipo centrífuga doméstica. $\mathrm{O}$ teor de sólidos solúveis totais (SST) e o teor de acidez titulável (AT) foram obtidos pela metodologia proposta por Pregnolatto \& Pregnolatto (1985). A determinação do $\mathrm{pH}$ foi realizada em medidor de $\mathrm{pH}$ de bancada microprocessado modelo TEC-11 (Tecnal, Piracicaba, SP). A colheita, no primeiro ciclo, foi realizada aos 123 dias após a poda de produção das videiras, e, no segundo ciclo, aos 127 dias após a poda.

Para as análises da atividade enzimática de quitinase e catalase, a coleta das folhas foi realizada em três períodos. Na safra de 2011, foi realizada 24 horas após a segunda aplicação (primeira coleta), 24 horas antes

Tabela 1. Componentes do óleo essencial de alecrim (Rosmarinus officinalis), identificados por CG-EM, e seus respectivos teores expressos em normalização de área ${ }^{(1)}$.

\begin{tabular}{lccc}
\hline Componentes & $\mathrm{t}_{\mathrm{r}}(\mathrm{min})$ & $\mathrm{IK}$ & Teor $(\%)$ \\
\hline$\alpha$-pineno & 12,72 & 930,94 & 12,00 \\
Canfeno & 13,40 & 943,46 & 4,08 \\
$\beta$-pineno & 14,91 & 971,27 & 3,03 \\
1-octen-3-ol & 15,58 & 983,61 & 0,13 \\
$\beta$-mirceno & 15,97 & 990,79 & 1,24 \\
A-terpineno & 17,17 & $1.013,36$ & 0,44 \\
1,8 cineol (eucaliptol) & 18,10 & $1.031,11$ & 44,39 \\
$\gamma$-terpineno & 19,45 & $1.056,87$ & 0,47 \\
Terpinoleno & 20,94 & $1.085,31$ & 0,24 \\
Linalol & 21,77 & $1.101,22$ & 0,93 \\
Cânfora & 23,90 & $1.144,69$ & 19,75 \\
Borneol & 24,85 & $1.164,08$ & 3,22 \\
Terpineno-4-ol & 25,39 & $1.175,10$ & 0,56 \\
$\alpha$-terpineol & 26,14 & $1.190,41$ & 2,33 \\
Verbenona & 26,92 & $1.203,46$ & 0,07 \\
Acetato de bornila & 30,51 & $1.243,58$ & 0,37 \\
$\beta$-cariofileno & 36,30 & $1.418,14$ & 4,53 \\
$\alpha$-humeleno & 37,63 & $1.450,74$ & 0,38 \\
\hline
\end{tabular}

${ }^{(1)}$ CG-EM, cromatografia gasosa acoplada a espectrometria de massa; $t_{\mathrm{r}}$, tempo de retenção; IK, índices de retenção de Kovats. da terceira aplicação (segunda coleta) e 24 horas após a terceira aplicação (terceira coleta). Na safra de 2012, em razão da alta pluviosidade no período experimental, a coleta do material vegetal foi realizada 24 horas após a quarta aplicação (primeira coleta), 24 horas antes da quinta aplicação (segunda coleta) e 24 horas após a quinta aplicação (terceira coleta). As coletas foram realizadas para as doses do óleo essencial de alecrim e os tratamentos Tween $80 \%$ e acibenzolar-S-metil. As análises foram realizadas no Laboratório de Fisiologia do Parasitismo da UEM.

O extrato enzimático foi obtido por meio da maceração de $1,0 \mathrm{~g}$ de folhas de videira com nitrogênio líquido e, em seguida, foi homogeneizado mecanicamente em $4,0 \mathrm{~mL}$ de tampão fosfato de potássio $50 \mathrm{mmol} \mathrm{L}^{-1}(\mathrm{pH} 7,0)$ contendo $0,1 \mathrm{mmol} \mathrm{L}^{-1}$ EDTA e $1 \%(\mathrm{p} / \mathrm{p})$ de polivinilpirrolidona (PVP), em almofariz. $\mathrm{O}$ homogenato foi centrifugado a $15.000 \mathrm{~g}$ durante $30 \mathrm{~min}$, a $4^{\circ} \mathrm{C}$, e o sobrenadante obtido foi considerado como extrato enzimático, o qual foi armazenado a $-20^{\circ} \mathrm{C}$, até a realização das análises.

O conteúdo proteico foi determinado pelo método de Bradford (1976), e a quitinase foi avaliada por meio da liberação de fragmentos solúveis de quitina carboximetilada marcada com remazol brilhante violeta CM-chitin-RBV (Loewe Biochemica $\mathrm{GmbH}$, Sauerlach, Alemanha) (Wirth \& Wolf, 1990). A atividade da catalase (EC 1.11.1.6) foi quantificada pelo método de Góth (1991), modificado por Tománková et al. (2006), por meio do complexo estável formado por molibdato de amônio com peróxido de hidrogênio (Abs405).

Os resultados obtidos foram submetidos à análise de variância e, quando significativos, as médias foram comparadas pelo teste de Tukey e pela análise de regressão polinomial, a 5\% probabilidade, com uso do programa estatístico Sisvar (Ferreira, 2011).

\section{Resultados e Discussão}

Houve efeito quadrático em função das doses do óleo essencial de alecrim para AACPD da mancha da folha da videira, em ambos os ciclos (Figura $1 \mathrm{~A}$ e B). A dose de $500 \mu \mathrm{L} \mathrm{L}^{-1}$ do óleo apresentou decréscimo de aproximadamente $57 \%$, quando comparada à testemunha, mas não diferiu do tratamento químico na safra de 2011 (Figura 1 A). No segundo ciclo (2012), observou-se comportamento similar: as doses de 500, 
1.000 e $2.000 \mu \mathrm{L} \mathrm{L}^{-1}$ do óleo essencial apresentaram decréscimo de aproximadamente 39,35 e $33 \%$ em relação à testemunha e não diferiram dos tratamentos calda bordalesa e acibenzolar-S-metil, embora tenham sido inferiores ao tratamento químico, que reduziu em $79 \%$ a AACPD (Figura $1 \mathrm{~B}$ ).

A severidade do míldio, representada pela AACPD, também apresentou efeito quadrático em função das doses do óleo essencial, sendo que a dose de $2.000 \mu \mathrm{L} \mathrm{L}^{-1}$ reduziu em $49 \%$ a severidade, quando comparada à testemunha, não tendo diferido do tratamento com mancozebe (Figura $1 \mathrm{C}$ ). Resultados semelhantes foram obtidos no segundo ano, em que a dose de $2.000 \mu \mathrm{L} \mathrm{L}^{-1}$ do óleo reduziu a severidade da doença em aproximadamente 44\%, em comparação à testemunha, sem diferença significativa para $\mathrm{o}$ tratamento mancozebe (Figura $1 \mathrm{D}$ ). O Tween $80 \%$, utilizado como adjuvante, não influenciou o controle das doenças causadas por $P$. vitis e $P$. viticola.

Em 2011, verificou-se menor severidade da mancha da folha e do míldio da videira em relação à safra 2012. Como boa parte do ciclo produtivo da videira em 2012 ocorreu no período chuvoso com $510 \mathrm{~mm}$, tendo atingido umidade relativa de aproximadamente $70 \%$ (Instituto Tecnológico Simepar, 2012), provavelmente houve o favorecimento da severidade para ambas as doenças. Nesse sentido, o óleo essencial de alecrim mostrou ser eficaz no controle de doenças
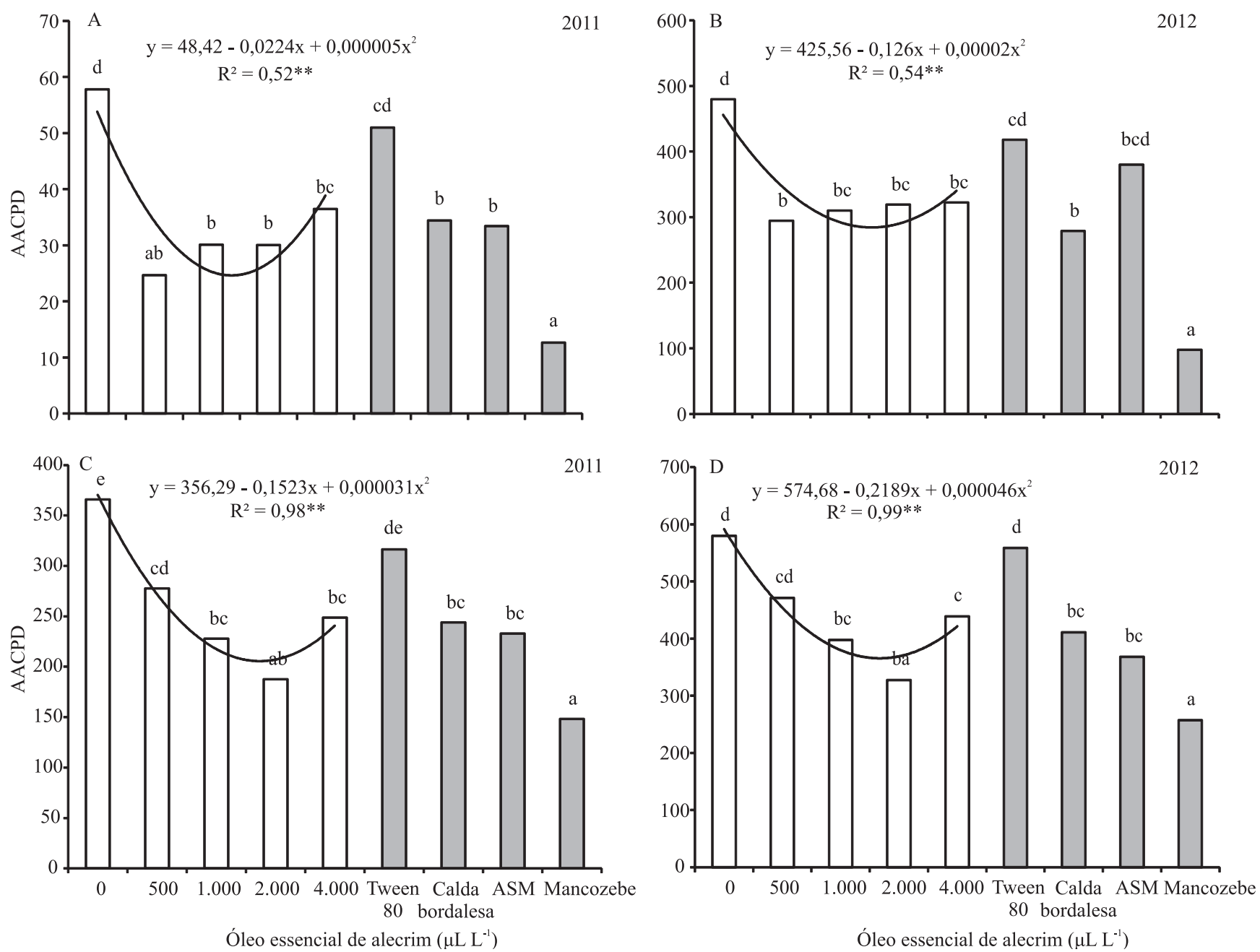

Figura 1. Severidade da mancha da folha (A e B) e do míldio (C e D) em videiras (Vitis labrusca) 'Isabel' submetidas a diferentes doses do óleo essencial de alecrim (Rosmarinus officinalis), nas safras consecutivas de 2011 e 2012. Análise de regressão apenas para as doses do óleo essencial. Para os outros tratamentos, médias seguidas por letras iguais não diferem pelo teste de Tukey, a 5\% de probabilidade. AACPD, área abaixo da curva de progresso da doença; ASM, acibenzolar-S-metil. 
da videira, mesmo em condições propícias para o seu desenvolvimento.

Não há relatos da aplicação de óleos essenciais no controle de doenças de videira em experimentos desenvolvidos em campo. Entretanto, Dagostin et al. (2010) demonstram que o extrato etanólico de plantas medicinais, como a sálvia (Salvia officinalis L.) - planta pertencente a mesma família do alecrim, Lamiaceae -, pode ser uma alternativa no controle de doenças da videira, pois a aplicação do extrato reduziu em $63 \%$ a AACPD do míldio em folhas de videira e em $94 \%$ a incidência da doença em cachos de uva.

O potencial protetor do extrato aquoso de alecrim contra a cladosporiose em plantas de tomateiro (Lycopersicon esculentum Mill.), em casa de vegetação, foi relatado por Itako et al. (2009), que observaram menor número de lesões nas folhas tratadas com 10 e $20 \%$ do extrato aquoso de alecrim e submetidas à inoculação do que na testemunha. Vigo et al. (2009), em trabalho com óleo essencial de $R$. officinalis a $0,5 \%$, verificaram que a severidade do crestamento bacteriano comum do feijoeiro (Xanthomonas axonopodis pv. phaseoli) não apresentou diferença significativa em relação à testemunha (água), em razão da baixa concentração do óleo essencial utilizada.

$\mathrm{Na}$ primeira colheita, as doses do óleo essencial não apresentaram efeito significativo na massa dos cachos (Figura $2 \mathrm{~A}$ ); contudo, para número de cachos por planta e produtividade, observaram-se valores máximos para as doses estimadas do óleo essencial de alecrim, de 1.604 e $1.334 \mu \mathrm{L} \mathrm{L}^{-1}$, respectivamente (Figura $2 \mathrm{C}$ e E). As doses de 1.000 e $2.000 \mu \mathrm{L} \mathrm{L}^{-1}$ do óleo essencial de alecrim apresentaram aumento de 58 e $90 \%$, respectivamente, para número de cachos e produtividade, quando comparadas à testemunha, mas não diferiram do tratamento químico.

$\mathrm{Na}$ segunda colheita, para massa de cachos, houve efeito quadrático em função das doses do óleo essencial de alecrim, sendo que a dose estimada para o valor máximo foi de $2.965 \mu \mathrm{L} \mathrm{L}^{-1}$ (Figura $2 \mathrm{~B}$ ). Para o número de cachos e a produtividade, observou-se efeito linear positivo (Figura $2 \mathrm{D}$ e F). O tratamento com $4.000 \mu \mathrm{L} \mathrm{L}^{-1}$ do óleo de alecrim proporcionou aumentos de 95 e 142\% para número de cachos por planta e produtividade, respectivamente, não tendo diferido significativamente dos tratamentos acibenzolar-S-metil, calda bordalesa e mancozebe.
Resultados semelhantes foram obtidos por Becker et al. (2004), que, ao avaliar o potencial de extratos aquosos de diversas plantas no controle de doenças de final de ciclo, causadas por S. glycines, C. kikuchii e M. difusa, em soja, em condições de campo, concluíram que o extrato de $R$. officinalis a 5\% apresentou aumento de $13 \%$ na produção $\left(\mathrm{kg} \mathrm{ha}^{-1}\right)$, quando comparado ao tratamento químico. Segundo Dagostin et al. (2010), plantas de videira 'Cabernet Sauvignon' tratadas com $50 \mathrm{~mL} \mathrm{~L}^{-1}$ do extrato etanólico de sálvia apresentaram aumento maior que $100 \%$ na produção por planta do que a testemunha, em dois anos consecutivos de avaliação. Os autores também relataram aumento de 97\% para massa dos cachos em plantas tratadas com $50 \mathrm{~mL} \mathrm{~L}^{-1}$ do extrato etanólico de sálvia, em relação à testemunha.

Nas duas safras, observou-se que as doses do óleo essencial de alecrim não influenciaram as características químicas da uva. Os valores médios obtidos, em 2011, foram de: 1,102\% de ácido tartárico (AAT); 15,28 ${ }^{\circ}$ Brix, próximo de 15; e pH igual a 3,0. Em 2012, os valores médios observados foram de: $0,704 \%$ de AAT, $12,74^{\circ}$ Brix, relação SST/ATT (índice de maturação) de 18,89 e pH 3,05. Esses resultados estão dentro dos limites estabelecidos para a elaboração de sucos de uva de qualidade (Sato et al., 2008).

Para a atividade das quitinases, em 2011, houve efeito quadrático em função das doses do óleo essencial de alecrim, para todos os períodos de avaliação, exceto para 24 horas após a terceira pulverização (Figura 3 A e C). As doses estimadas com valores máximos foram de 1.544 e $2.097 \mu \mathrm{L} \mathrm{L}^{-1}$, para os períodos de 24 horas após a segunda pulverização e 24 horas antes da terceira pulverização, respectivamente. Os maiores percentuais (164 e 816\%) no aumento da atividade das quitinases foram observados na dose de $1.000 \mu \mathrm{L} \mathrm{L}^{-1}$ após 24 horas da segunda aplicação e 24 horas antes da terceira pulverização, respectivamente, não tendo diferido significativamente do tratamento acibenzolar-S-metil, que promoveu aumento de $120 \mathrm{e}$ $408 \%$ em comparação à testemunha.

Na segunda safra (2012), houve efeito linear positivo em função das doses do óleo essencial de alecrim na atividade das quitinases após 24 horas da pulverização dos tratamentos (Figura 3 B). A dose de 4.000 $\mu \mathrm{L} \mathrm{L}^{-1}$ propiciou aumento de $462 \%$, quando comparada à testemunha, tendo diferido significativamente do tratamento acibenzolar-S-metil, que aumentou em 
214\%. Nas 24 horas antes da aplicação dos tratamentos, verificou-se efeito quadrático em função das doses do óleo essencial de alecrim (Figura 3 D). A dose estimada para o valor máximo foi de $1.175 \mu \mathrm{L} \mathrm{L}^{-1} 24$ horas antes da pulverização dos tratamentos. No período de 24 horas após a quinta pulverização, não houve efeito significativo para essa variável.
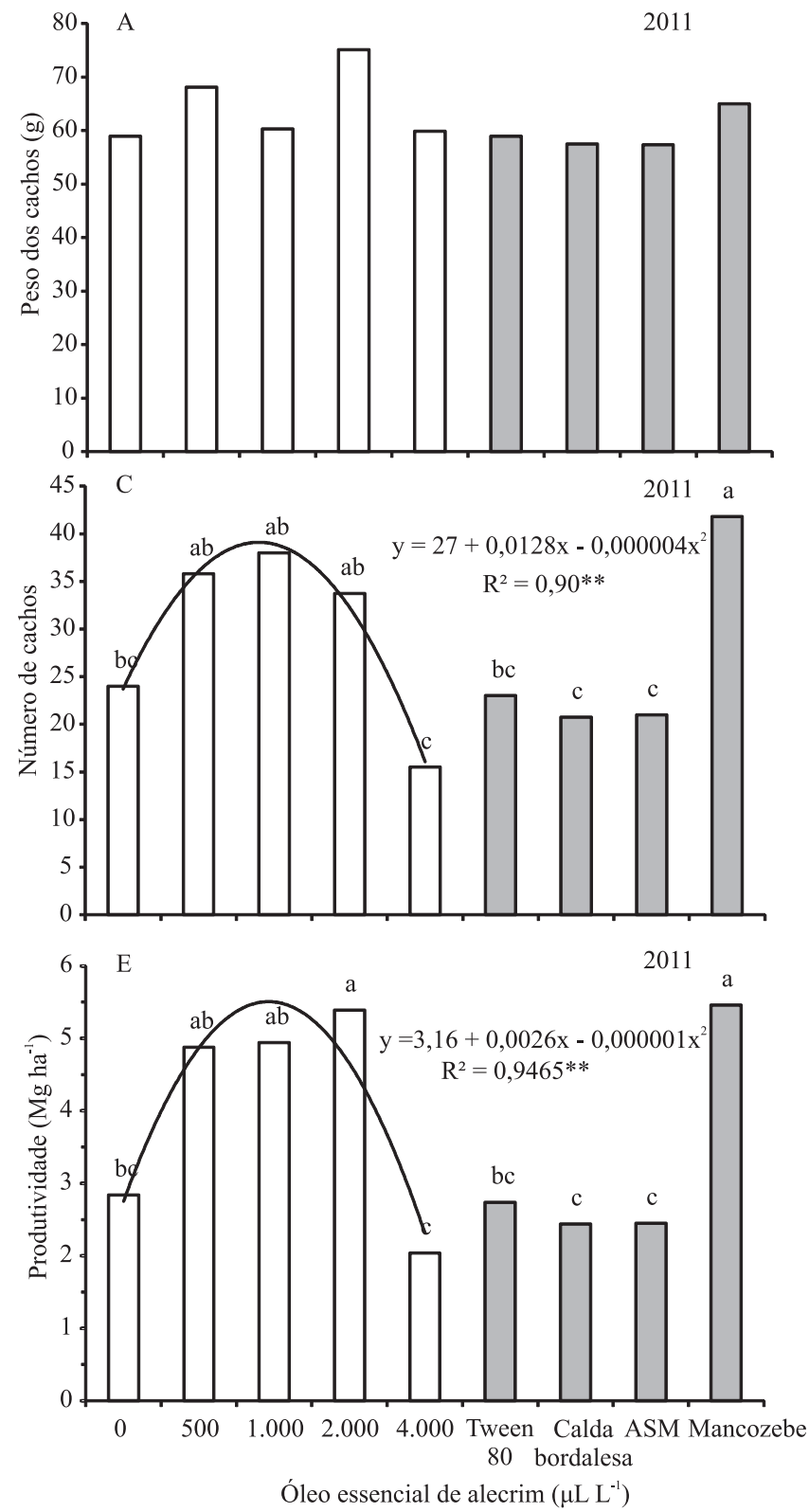

De acordo com Braga (2008), as enzimas quitinases, em ação conjunta com as $\beta$-glucanases, são eficientes em degradar a parede celular dos fungos. Além de deter o crescimento do patógeno, determinam a liberação simultânea de elicitores de fitoalexinas a partir do micélio do patógeno. Essas proteínas estão relacionadas aos mecanismos de defesa das plantas
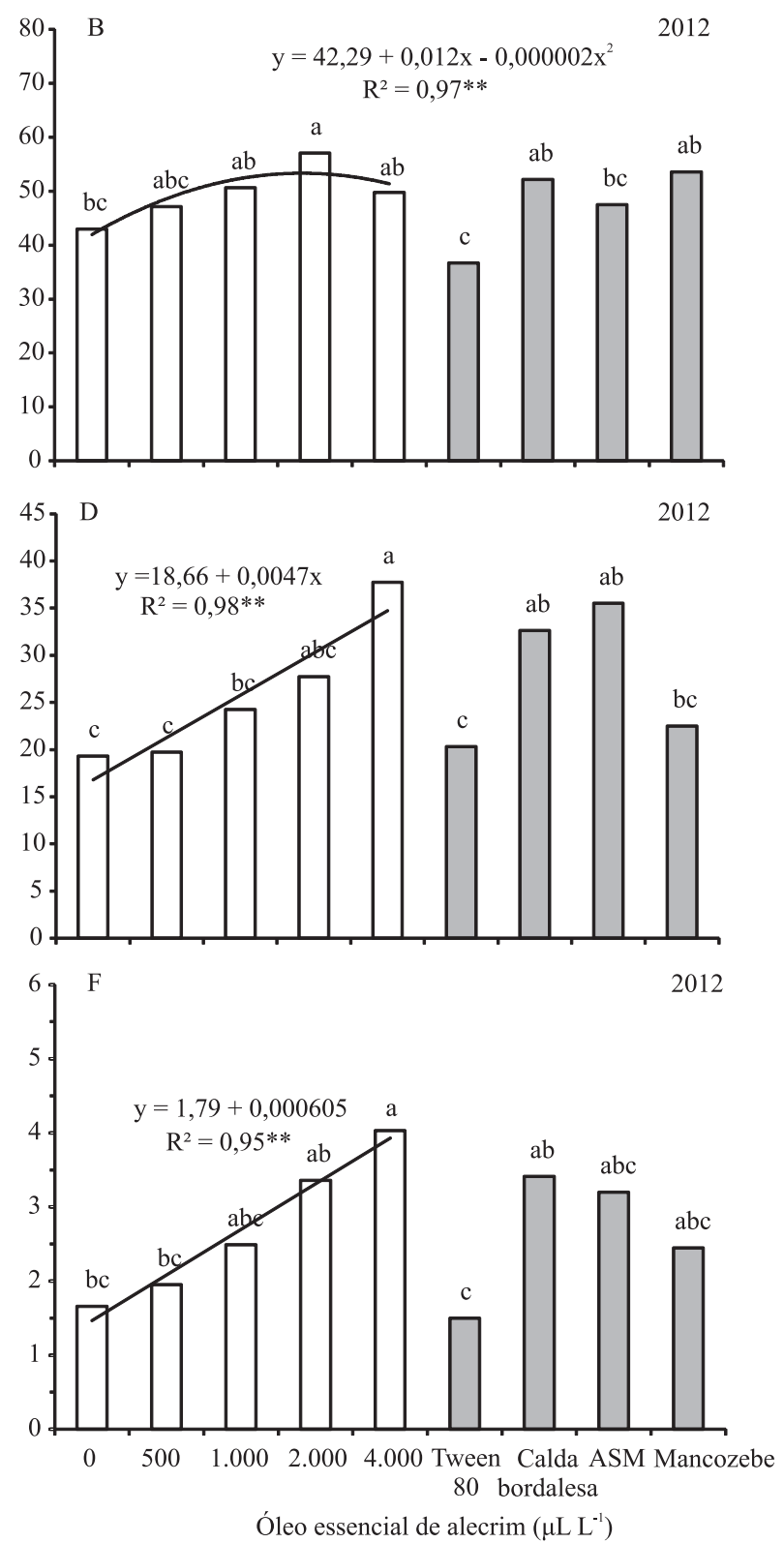

Figura 2. Peso de cacho (A e B), número de cachos (C e D) e produtividade (E e F) de uvas (Vitis labrusca) 'Isabel' submetidas a diferentes doses do óleo essencial de alecrim (Rosmarinus officinalis), nas safras consecutivas de 2011 e de 2012. Análise de regressão apenas para as doses do óleo essencial. Para os outros tratamentos, médias seguidas por letras iguais não diferem pelo teste de Tukey, a 5\% de probabilidade. ASM, acibenzolar-S-metil. 
contra patógenos e de indução de resistência (Ferreira et al., 2007). Os tratamentos com 1.000 e $2.000 \mu \mathrm{L} \mathrm{L}^{-1} \mathrm{do}$ óleo essencial não apresentaram nenhuma atividade da enzima catalase 24 horas após a segunda pulverização, em 2011 (Figura 4 A). Esses tratamentos não diferiram do tratamento com acibenzolar-S-metil, que reduziu em $76 \%$ a atividade da catalase. Na segunda coleta, realizada 24 horas antes da terceira pulverização, as doses de 500 e $1.000 \mu \mathrm{L} \mathrm{L}^{-1}$ apresentaram menor atividade enzimática, com redução de aproximadamente 80 e $76 \%$, em comparação à testemunha, não tendo diferido do tratamento acibenzolar-S-metil (Figura 4 C). No período de 24 horas após os tratamentos, a dose de $500 \mu \mathrm{L} \mathrm{L}^{-1}$ reduziu em $48 \%$, em relação ao valor verificado para a testemunha, e diferiu significativamente do indutor comercial (Figura 4 E).

$\mathrm{Na}$ segunda safra, houve efeito quadrático em função das doses do óleo, em todos os tempos de avaliação (Figura 4 B, D e F). A dose de $2.000 \mu \mathrm{L} \mathrm{L}^{-1}$ não promoveu a atividade da enzima catalase, quando comparada à testemunha, e diferiu do tratamento acibenzolar-S-metil, que reduziu aproximadamente $35 \%$ da atividade da catalase 24 horas após a quarta pulverização e 24 horas antes da quinta pulverização (Figura 4 B e D). Após 24 horas da aplicação dos tratamentos, as doses de $1.000,2.000$ e $4.000 \mu \mathrm{L} \mathrm{L}^{-1}$ reduziram em 81,73 e $73 \%$ a mais que o valor obtido para a testemunha, não tendo diferido significativamente do tratamento acibenzolar-S-metil (Figura $4 \mathrm{~F}$ ).

A principal função das catalases é degradar o peróxido de hidrogênio $\left(\mathrm{H}_{2} \mathrm{O}_{2}\right)$ em plantas (Apel \& Hirt, 2004), ao atuar como sinalizador na resposta de defesa da planta e no reforço da parede celular, pela ligação cruzada de proteína estrutural ou fenólica, ao formar uma barreira mecânica efetiva (Resende et al., 2003). A redução da atividade da enzima catalase
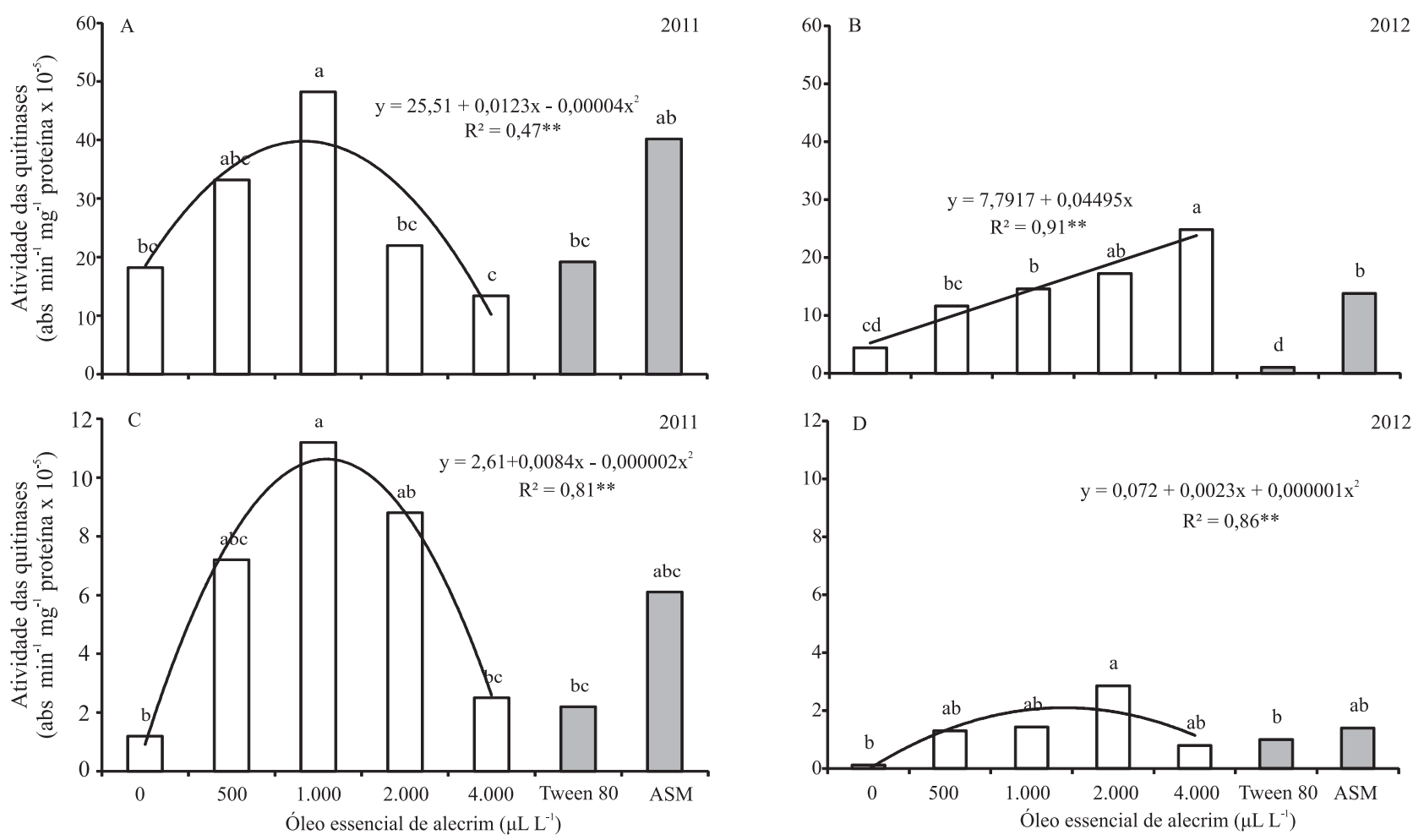

Figura 3. Atividade das quitinases em folhas de videira (Vitis labrusca) 'Isabel' submetidas a diferentes doses do óleo essencial de alecrim (Rosmarinus officinalis), nas safras de 2011 e 2012. Em 2011: A, 24 horas após a segunda pulverização (primeira coleta); C, 24 horas antes da terceira pulverização (terceira coleta); e, em 2012: B, 24 horas após a quarta pulverização (primeira coleta); D, 24 horas antes da quinta pulverização (terceira coleta). Análise de regressão apenas para as doses do óleo essencial. Para os outros tratamentos, médias seguidas por letras iguais não diferem pelo teste de Tukey, a 5\% de probabilidade. ASM, acibenzolar-S-metil. 
pode estar relacionada ao acúmulo de peróxido de hidrogênio, o que aumenta a produção de espécies reativas de oxigênio, que reduzem a severidade das doenças (Torres et al., 2006).

Os componentes identificados, com os seus tempos de retenção, índices de retenção de Kovats e teor na amostra, estão descritos na Tabela 1. Foram identificados 18 componentes presentes no óleo essencial de alecrim. Os constituintes majoritários foram: 1,8 cineol (44,39\%), cânfora (19,75\%), $\alpha$-pineno (12\%), $\beta$-cariofileno $(4,53 \%)$ e canfeno $(4,08 \%)$, o que corresponde a $65 \%$ do total do óleo. Para Gachkar et al.
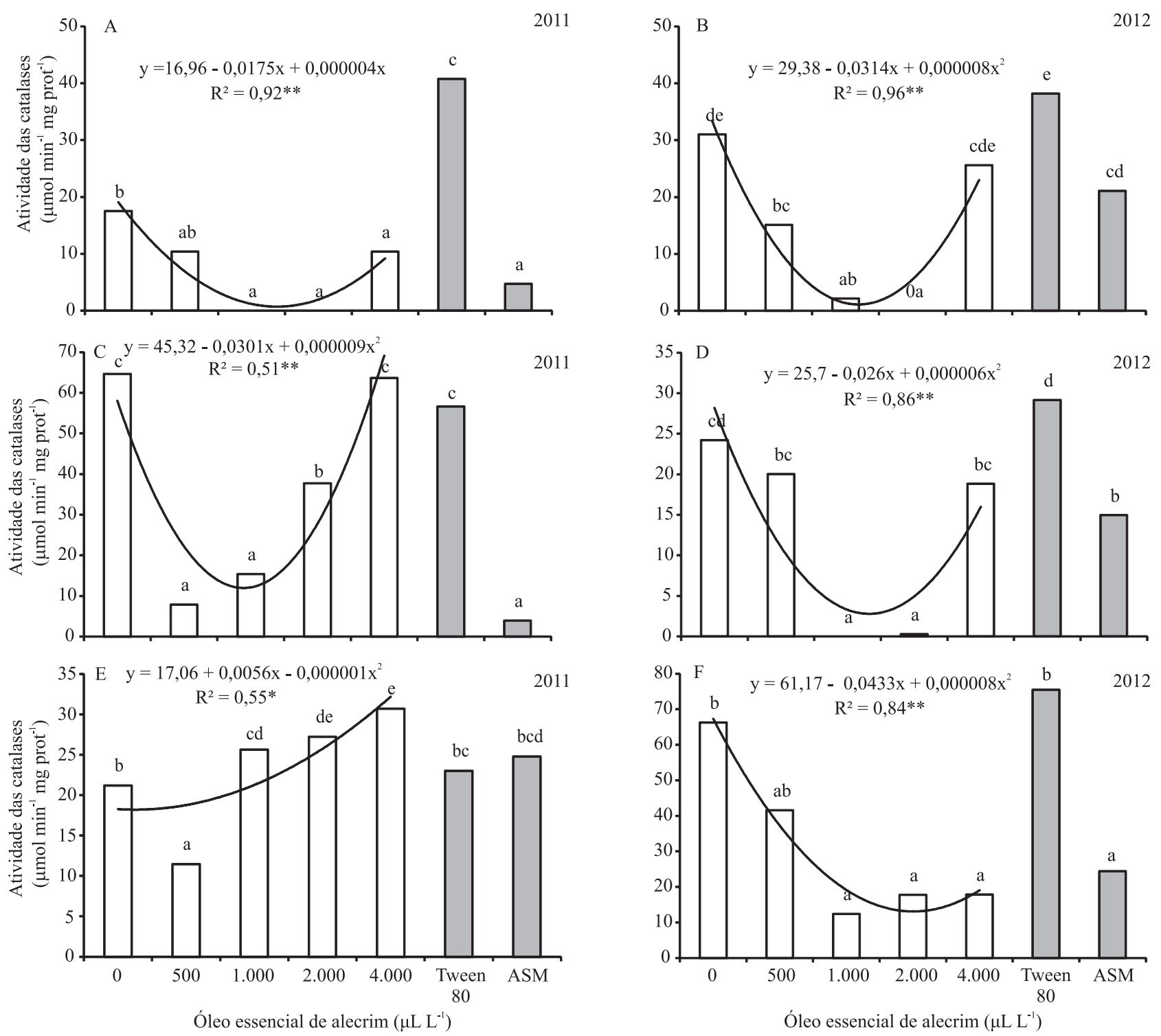

Figura 4. Atividade das catalases em folhas de videira (Vitis labrusca) 'Isabel' submetidas a diferentes doses do óleo essencial de alecrim (Rosmarinus officinalis), nas safras de 2011 e 2012. Em 2011: A, 24 horas após a segunda pulverização (primeira coleta); C, 24 horas antes da terceira pulverização (segunda coleta); E, 24 horas após a terceira pulverização (terceira coleta); e, em 2012: B, 24 horas após a quarta pulverização (primeira coleta); D, 24 horas antes da quinta pulverização (segunda coleta); F, 24 horas após a quinta pulverização (terceira coleta). Análise de regressão apenas para as doses do óleo essencial. Para os outros tratamentos, médias seguidas por letras iguais não diferem pelo teste de Tukey, a $5 \%$ de probabilidade. ASM, acibenzolar-S-metil. 
(2007), os metabólitos 1,8 cineol, $\alpha$-pineno, borneol e cânfora são ativos contra microrganismos.

Itako et al. (2009) constataram redução no número de lesões causadas por Cladosporium fulvum e uma possível indução de resistência, principalmente com uso de extratos brutos aquosos de Artemisia camphorata e R. officinalis.

O óleo essencial de alecrim mostrou ser eficiente no controle da mancha da folha e do míldio da videira em campo. Foi observada capacidade de indução da atividade da quitinase e da catalase, o que indica possibilidade da indução de resistência. O óleo essencial de alecrim pode ser uma alternativa promissora para o controle de doenças.

\section{Conclusões}

1. As doses de 500, 1.000 e $2.000 \mu \mathrm{L} \mathrm{L}^{-1}$ do óleo essencial de alecrim (Rosmarinus officinalis) reduzem a severidade da mancha da folha e do míldio da videira (Vitis labrusca).

2. As doses de 1.000 e $2.000 \mu \mathrm{L} \mathrm{L}^{-1}$ do óleo essencial de alecrim aumentam o número de cachos e a produtividade, e não influenciam as características químicas da uva.

3. As doses de 1.000 e $2.000 \mu \mathrm{L} \mathrm{L}^{-1}$ do óleo essencial de alecrim induzem resistência em videira, pelo aumento na atividade das quitinases e pela redução na atividade das catalases.

\section{Agradecimentos}

À Coordenação de Aperfeiçoamento de Pessoal de Nível Superior (Capes), pela bolsa concedida.

\section{Referências}

APEL, K.; HIRT, H. Reactive oxygen species: metabolism, oxidative stress, and signal transduction. Annual Review of Plant Biology, v.55, p.373-399, 2004. DOI: 10.1146/annurev. arplant.55.031903.141701.

AZEVEDO, L.A.S. de. Manual de quantificação de doenças de plantas. São Paulo: [s.n.], 1998. 114p.

BETTIOL, W.; MORANDI, M.A.B. Biocontrole de doenças de plantas: uso e perspectivas. Jaguariúna: Embrapa Meio Ambiente, 2009. 341p.

BRADFORD, M.M. A rapid and sensitive method for the quantitation of microgram quantities of protein utilizing the principle of protein-dye binding. Analytical Biochemistry, v.72, p.248-254, 1976. DOI: 10.1016/0003-2697(76)90527-3.
BRAGA, M.R. Fitoalexinas. In: PASCHOLATI, S.F.; LEITE, B.; STANGARLIN, J.R.; CIA, P. (Ed.). Interação planta-patógeno: fisiologia, bioquímica e biologia molecular. Piracicaba: FEALQ, 2008. p.305-346.

CAMPBELL, C.L.; MADDEN, L.V. Introduction to plant disease epidemiology. New York: John Wiley, 1990. 532p.

DAGOSTIN, S.; FORMOLO, T.; GIOVANNINI, O.; PERTOT, I.; SCHMITT, A. Salvia officinalis extract can protect grapevine against Plasmopara viticola. Plant Disease, v.94, p.575-580, 2010. DOI: 10.1094/ PDIS-94-5-0575.

DÍAZ DELlaVAlLE, P.; CABRERA, A.; ALEM, D.; LARRAÑAGA, P.; FERREIRA, F.; RIZZA, M.D. Antifungal activity of medicinal plant extracts against phytopathogenic fungus Alternaria spp. Chilean Journal of Agricultural Research, v.71, p.231-239, 2011. DOI: 10.4067/S0718-58392011000200008.

FERREIRA, D.F. Sisvar: a computer statistical analysis system. Ciência e Agrotecnologia, v.35, p.1039-1042, 2011. DOI: 10.1590/S1413-70542011000600001.

FERREIRA, R.B.; MONTEIRO, S.; FREITAS, R.; SANTOS, C.N.; CHEN, Z.; BATISTA, L.M.; DUARTE, J.; BORGES, A.; TEIXEIRA, A.R. The role of plant defence proteins in fungal pathogenesis. Molecular Plant Pathology, v.8, p.677-700, 2007. DOI: 10.1111/J.1364-3703.2007.00419.X.

GACHKAR, L.; YADEGARI, D.; REZAEI, M.B.; TAGHIZADEH, M.; ASTANEH, S.A.; RASOOLI, I. Chemical and biological characteristics of Cuminum cyminum and Rosmarinus officinalis essential oils. Food Chemistry, v.102, p.898-904, 2007. DOI: 10.1016/j.foodchem.2006.06.035.

GÓTH, L. A simple method for determination of serum catalase activity and revision of reference range. Clinica Chimica Acta, v.196, p.143-151, 1991. DOI: 10.1016/0009-8981(91)90067-M.

INSTITUTO TECNOLÓGICO SIMEPAR. Instituto Tecnológico Simepar. Curitiba: Centro Politécnico da UFPR, 2012.

ITAKO, A.T.; SCHWAN-ESTRADA，K.R.F.; STANGARLIN J.R.; TOLENTINO JÚNIOR, J.B.; CRUZ, M.E.S. Controle de Cladosporium fulvum em tomateiro por extratos de plantas medicinais. Arquivos do Instituto Biológico, v.76, p.75-83, 2009.

LENZ, G.; COSTA, I.D. da; BALARDIN, R.S.; MARQUES, L.N.; ARRUÉ, A.; STEFANELO, M.S.; ZEMOLIN, C.R. Elaboração e validação de escala diagramática para quantificação da mancha de isariopsis da videira. Ciência Rural, v.39, p.2301-2308, 2009. DOI: $10.1590 / \mathrm{S} 0103-84782009000800005$.

PREGNOLATTO, W.; PREGNOLATTO, N.P. (Coord.). Normas analíticas do Instituto Adolfo Lutz: métodos químicos e físicos para análise dos alimentos. 3.ed. São Paulo: Instituto Adolfo Lutz, 1985. v.1, 332p.

RESENDE, M.L.V.; SALGADO, S.M.L.; CHAVES, Z.M. Espécies ativas de oxigênio na resposta de defesa de plantas a patógenos. Fitopatologia Brasileira, v.28, p.123-130, 2003. DOI: 10.1590/ S0100-41582003000200001.

RIBEIRO,D.S.; MELO, D.B.; GUIMARÃES,A.G.; VELOZO,E.S. Avaliação do óleo essencial de alecrim (Rosmarinus officinalis L.) como modulador da resistência bacteriana. Semina: Ciências 
Agrárias, v.33, p.687-696, 2012. DOI: 10.5433/1679-0359.2012v3 $3 \mathrm{n} 2 \mathrm{p} 687$.

SANTOS, A.C.A. dos; ROSSATO, M.; SERAFINI, L.A.; BUENO, M.; CRIPPA, L.B.; SARTORI, V.C.; MOYNA, P. Efeito fungicida dos óleos essenciais de Schinus molle L. e Schinus terebinthifolius Raddi, Anacardiaceae, do Rio Grande do Sul. Revista Brasileira de Farmacognosia, v.20, p.154-159, 2010. DOI: 10.1590/ S0102-695X2010000200003.

SANTOS, H.G. dos; JACOMINE, P.K.T.; ANJOS, L.H.C. dos; OLIVEIRA, V.A. de; OLIVEIRA, J.B. de; COELHO, M.R.; LUMBRERAS, J.F.; CUNHA, T.J.F. (Ed.). Sistema brasileiro de classificação de solos. 2.ed. Rio de Janeiro: Embrapa Solos, 2006. $306 \mathrm{p}$.

SATO, A.J.; SILVA, B.J. da; SANTOS, C.E. dos; BERTOLUCCI, R.; SANTOS, R. dos; CARIELO, M.; ROBERTO, S.R. Características físico-químicas e produtivas das uvas 'Isabel' e 'BRS-Rúbea' sobre diferentes porta-enxertos na região norte do Paraná. Revista Brasileira de Fruticultura, v.30, p.553-556, 2008. DOI: 10.1590/S0100-29452008000200050.

SCHWAN-ESTRADA, K.R.F.; STANGARLIN, J.R.; KUHN, O.J.; BONALDO, S.M. Uso de extratos vegetais e cogumelos na indução de resistência de plantas. In: RODRIGUES, F. de Á.; FORTUNATO, A.A.; RESENDE, R.S. Indução de resistência em plantas a patógenos. Viçosa: Ed. da UFV, 2012. p.9-28.

SÔNEGO, O.R.; GARRIDO, L. da R.; GRIGOLETTI JUNIOR, A. Doenças fúngicas. In: FARJADO, T.V.M. (Ed.). Uvas para o processamento: fitossanidade. Brasília: Embrapa Informação Tecnológica, 2003. p.11-44.

SOYLU, E.M.; SOYLU, S.; KURT, S. Antimicrobial activities of the essential oils of various plants against tomato late blight disease agent Phytophthora infestans. Mycopathologia, v.161, p.119-128, 2006. DOI: $10.1007 / \mathrm{s} 11046-005-0206-\mathrm{z}$.

TALAMINI, V.; STADNIK, M.J. Extratos vegetais e de algas no controle de doenças de plantas. In: STADNIK, M.J.; TALAMINI, $\mathrm{V}$. (Ed.). Manejo ecológico de doenças de plantas. Florianópolis: Ed. da UFSC, 2004. p.45-62.

TOMÁNKOVÁ, K.; LUHOVÁ, L.; PETØIVALSKÝ, M.; PEÈ, P.; LEBEDA, A. Biochemical aspects of reactive oxygen species formation in the interaction between Lycopersicon spp. and Oidium neolycopersici. Physiological and Molecular Plant Pathology, v.68, p.22-32, 2006. DOI: 10.1016/j.pmpp.2006.05.005.

TORRES, M.A.; JONES, J.D.G.; DANGL, J.L. Reactive oxygen species signaling in response to pathogens. Plant Physiology, v.141, p.373-378, 2006. DOI: 10.1104/pp.10.

VIGO, S.C.; MARINGONI, A.C.; CÂMARA, R. de C.; LIMA, G.P.P. Ação de tinturas e óleos essenciais de plantas medicinais sobre o crestamento bacteriano comum do feijoeiro e na produção de proteínas de indução de resistência. Summa Phytopathologica, v.35, p.293-304, 2009. DOI: 10.1590/S0100-54052009000400007.

WANG, W.; WU, N.; ZU, Y.G.; FU, Y.J. Antioxidative activity of Rosmarinus officinalis L. essential oil compared to its main components. Food Chemistry, v.108, p.1019-1022, 2008. DOI: 10.1016/j.foodchem.2007.11.046.

WIRTH, S.J.; WOLF, G.A. Dye-labelled substrates for the assay and detection of chitinase and lysozyme activity. Journal of Microbiological Methods, v.12, p.197-205, 1990. DOI: 10.1016/0167-7012(90)90031-Z.

WORWOOD, S. Aromaterapia: um guia de A a Z para o uso terapêutico dos óleos essenciais. São Paulo: Best Seller, 1995. $251 \mathrm{p}$.

Recebido em 28 de fevereiro de 2014 e aprovado em 28 de abril de 2014 